\title{
Comparative Analysis of Social and Conventional Media Patronage among University Students: A Case Study of University of Maiduguri
}

\author{
Mohammed Auwal Umar, Fredrick Wilson* \\ Department of Mass Communication University of Maiduguri, Borno State Nigeria
}

*Corresponding Author: Fredrick Wilson, Department of Mass Communication University of Maiduguri, Borno State Nigeria

\begin{abstract}
The study was conducted to comparatively analyze the patronage of social and conventional media among students; a case study of University of Maiduguri. The study is significant because it helped in unveiling the paradigm shift in respect of social and conventional media patronage. The objectives of the study areto examine the level of patronage of conventional and social media by students of University of Maiduguri, to find out the reasons for the preference of either social or conventional media by University of Maiduguri students, to determine the reliance of the students on either social media or conventional media. Uses and gratification theory was adopted as philosophical guide. Survey was the research method used, with questionnaire as instrument that was purposively distributed among 200 respondents. The survey established that patronage of media (either social or conventional) among students is absolutely positive. Simply put, every student patronizes either social or conventional media. Social media has higher level of patronage compared to the conventional media among the students and their patronage. There is high commitment of the students to the type of media they patronize. According to this finding, the higher number obtained from patronage of social media influence level of commitment in this finding. This further means that degree of patronage of social media is higher than conventional media. The amount of time audience allocates to the patronage of media either social or conventional is huge. This finding is also influenced by the first finding regarding the number of those that patronize conventional and social media. This means the amount of time spent on social media is higher than the conventional media by the students. There is exorbitant preference to the social media than conventional media. There is still significant number of audience who prefer the conventional media to social media. Audiences prefer conventional media because of accuracy and reliability of information. Professionalism and standard in ethics, spelling and grammar are also influential reason on their preference of conventional media. Audiences prefer social media for instant messages and updates found on the platforms. However, interactivity and participatory nature play significant role on their preference of social media. Each of the media influence its audience based peculiar characteristic and features which pilot the level of patronage. Because some like more interactivity and participation, the social media is waxing strong in this respect while the conventional media keep soaring higher among those who prefer reliable and accurate information that been professionally verified. Most of the audiences rely on information they receive from the social media even though significant number (39.5\%) still doubt the reliability of such information. Almost all audiences rely on conventional media. The number (6\%) of those who do not rely on such information is less or no significance. The degrees of reliance vary across the audience.
\end{abstract}

Keywords: Conventional Media, Patronage, Preference, Reliance, Social Media, Students.

\section{INTRODUCTION}

History has it that before the advent of radio, television and newspaper, distribution of information was narrow and slow. This not with standing is attributed to the socio-economic structure of the society. Even after the advent of conventional media, the patronage remained economically driven and motivated. This means, affording television set, radio set and purchasing newspaper is highly concentrated in the hands of economically viable audience. The eventuality played significant role on the audience of mass media. As technology grew to a strong level, the conventional media access became cheaper. For instance, radio became the most ubiquitous communication gadget mainly because of the countless mediums through which its signals can be accessed. Today, mobile phones, cars, tricycle and other vehicles are now embedded with radio decoders. This tells of how available 
and cheap radio decoder has become. On another lane, television viewing centers and cinemas played huge roles in simplifying access to television content. Newspaper is not left out in this aspect, considering the popular tradition in urban areas of "Free Readers" who gather at newsstands to read newspapers and stage public discourse afterward.

The above picture presents briefly how conventional media patronage evolved and the factors that influenced its evolution. Interestingly, some of the old factors still play significant roles in its ceaseless evolution/patronage which is why we have the new media today. Many pessimistic scholars presumed that the paradigm shift in media climate could be at the detriment of the conventional media (Yeshua, 2000; Stern, 1999; Kuyucu, 2014). There are some who argued that the end of the conventional media is near. Remarkably, the conventional media is waxing stronger every day and simultaneously sustaining the damage and injuries caused by the emergence of the new media. Their sustenance cannot be separated from the context of validity and reliability than the new media. Despite the simplicity, portability, interactivity and cheapness of new media, the conventional media has been able to maintain its years to year's status core as the most reliable source of information to the public, hence, the degree of patronage and reliance keeps waxing higher and stronger routinely.

On the other hand, the new media is a notion that defines modern channels through which information is accessed, communication made is easy and interactivity enhanced. The concept of new media has its own component. These include internet, computers, Smartphone, social media and social networking sites etc. Internet is online-based which facilitates all virtual connectivity. Mobile phones, computers and other devices are hardware connected for the purpose of resources sharing online whilst social media are platforms through which information are shared, interactions are enabled and meeting new people guaranteed.

Dewing (2010) define "social media as the wide range of internet-based and mobile service that allow users to participate in online exchanges, contribute user-created content or join online communities". Social media also refers to the use of web-based and mobile technologies to turn communication into interactive dialogue and they can take many different forms, including internet forums, weblogs, social blogs, wikis, podcasts, photographs or pictures, video, rating and social bookmarking (European Commission, 2012). These definitions suggested some attributes that make social media at the fore front of audience patronage. These attributes include online-based, mobility, portability and participation. On this brink, many opinions and visible happenings continue to make one ponder as to which of two; conventional or social media gain higher patronage. The motives or incentives that attract audience toward either of the two are also questionable. This prompted the desire to inquire, thus, this study.

However, there are requirements for the use of social media, literacy is key. This is one of the reasons why the study was directed to an academic institution where literacy is at its peak. It is also an environment known with the tradition of media consumption by students and staff. For the purpose of proper direction and precision, the following questions stand as key background for the study; who patronize social media and why? Who patronize conventional media and why? Why the preference of either conventional or social media? What is the extent of their reliabilities on either social media or conventional media? These questions were drawn from studies conducted on use of social media, its increase among students as well as its impact on their academic performance (Acheaw\& Larson, 2015; Larson, 2014).

\section{Statement of The Problem}

The entirety of mass media (whether radio, television, newspaper etc) depend on audience patronage. The rate of listenership, viewership and readership is directly related to audience patronage of a particular media organization. This however, determine popularity and to some extent attracts advertisers. It is on this backdrop that mass media strive to maintain their audience more especially at a time like this when alternative keeps emerging. This was contained in the findings of a study sponsored by "iSentia" (Mcnamara, 2014). Consequently, the emergence of new media (social media in this context) ushered in a shift of patronage from conventional to social media especially among the youth. They key findings of the study conducted by Mcnamara (2014) suggested striking social media patronage, social media influence in distorting traditional media model and the increase in adoption of social media over the conventional media. These studies suggested that social media use among 
students is on the increase. Ahmad (2016) also studied how social media is attempting to erase the traditional media (newspapers and magazines) from the industry. It is on this background that this study seeks to find answers by comparatively analyzing students' patronage of conventional and social media using University of Maiduguri as a case study.

\subsection{Objectives of the Study}

The study has the following objectives:

- To examine the level of patronage of conventional and social media by students of University of Maiduguri.

- To find out the reasons for the preference of either social or conventional media by Unimaid students.

- To determine the reliance of the students on either social media or conventional media.

\subsection{Research Questions}

- What is the level of patronage on conventional or social media by students of University of Maiduguri?

- Do Unimaid students prefer social media to conventional media?

- Do Unimaid students prefer conventional media to social media?

- Why do Unimaid students prefer either social media or conventional media?

- What are the reasons for the preference of either social media or conventional media?

- Do students rely on information they access on social media?

\subsection{Significance of the Study}

This study probes into media patronage on comparative scale. The comparative study weighted the level of patronage of the conventional media against the social media considering the paradigm shift in patronage. The result of the study will provide valuable contribution to the body of literature on the emergence, proliferation and adoption of ICTs among people of different location. Not just that, it will also provide a scientific understanding of the level of patronage of conventional media and the social media. from a theoretical angle, the findings of this study will also shed light on the position of pessimism expressed by some scholars regarding the emergence of social media and its presume effect on the sustenance of conventional media. In practice, the finding of this study will provide an insight to media practitioners both in conventional media and online on how well they can attract new and retain old audience. This is because the study also inquired into the reasons why the audiences prefer to patronize either social media or conventional media for their information needs.

\subsection{Scope of the Study}

The study is limited to University of Maiduguri, Borno State. The study tends to find answers comparatively on social and conventional media patronage among students of the University of Maiduguri. The researchers covered Faculty of Social Sciences only because of the purposive nature of the study. This is because the faculty is embedded with cadre of students who are highly related to the media in terms of listening, viewing, browsing and reading in order to get access to information. Example Political Science students are highly recommended to follow trends on the media in order to enhance their sense of analysis, students of Sociology are also related to the media in some other ways whilst students of the department of Mass Communication are most keen and enthusiastic about the media not for their leisure but for academic purposes too. These add to the expectation that a University student is presumed and ought to have access to the media than otherwise.

\section{LITERATURE REVIEW}

\subsection{Conceptual Analysis of Conventional Media}

Media are channels through which information is channeled to the target audience. Media is said to be as old as human being exist. So, its patronage goes the same long way. The concept of 'conventional 
media' has been argued upon so many scholars as to its meaning as well as its relationship and distinction with some closer terms. For instance, the concept of traditional media has been linked with the concept of conventional media. Similar case is apparent with other concepts like Folk media, nonelectronic media, analog media etc. This becomes significant to distinguish the concept of 'conventional media' from other concepts by establishing its exclusiveness in terms of attributes and operations.

According to Odun \&Utulu (2016) the traditional media refers to those methods' indicative of printbased newspaper and television. They include the electronic, the print and the narrowcast media with tremendous achievements over decades. In their definition newspaper, radio and television were considered the traditional media. The definition was coined by comparing it with the new media. Traditional in this context refers to the usual media which is directly proportional to the denotative meaning of conventional media. The conventional media is also termed "mass media". This is contained in the assertion of Onuoha (2012) who wrote that "Concisely, the term mass media simply translates to the modern means of giving news, opinion, education, entertainment and agenda-setting to large numbers of people, especially through radio, television, newspapers, magazines and films". This definition seems to be too limited to the mechanical devices that transmit and sometimes store the message (television cameras, radio microphones, printing presses) as it excludes the institutions that use these machines to transmit messages such as newspaper house, radio station, television network, or magazine firm. To this end, a complete understanding of the concept of conventional media must be viewed from angle of the combination of mechanical devices, institutions that operate as well as personnels that handle the huge responsibility of producing the content.

\subsection{Components and Types of Conventional Media}

There are three major components of conventional media. They are radio, television and newspapers/ magazine. They are however classified as types in some context. Each of the types has its own peculiar characteristics, operations, demand and audience, thus the difference in pattern of their patronage. For instance, the radio is patronized by listeners who can be both literate and illiterate provided they can comprehend the language of the broadcast. The language of the broadcast is now globally extended to reach more audience. Television has more features because it broadcast in audiovisual format whilst newspaper remained media for the elite because of its sophistication in content. This part will review scholars understanding and assertions about the major components of the conventional media.

\subsubsection{Newspaper/Magazine}

This is a print media established to serve news in a paper form. They were considered the first conventional media. its history clock from the establishment of Gutenberg Printing Press. In Nigerian context it dates back to the establishment of IweIrohin by Reverend Henry Townsend. Newspaper is a bulletin published in a folded loose (not bound) sheets that contain news, articles, pictures, cartoons and other elements in order to convey information in a journalistic standard.

\subsubsection{Radio}

Radio can be defined as a medium used for sending and receiving messages through the air using electronic waves. It is also about the activity of broadcasting programmes for people to listen to the programmes being broadcast (Idebi, 2008:1). Radio is an electronic medium through which a signal is transmitted to the airwave and received by the use of decoder. Its signals are transferred through either Amplitude Modulation (AM) or Frequency Modulation (FM) (Akinfeleye, 2011). It is one of the most scientific wonders of the 1920s which attracted many fans. According to Udomisor (2013) radio broadcasting is "an audio (sound) broadcasting service, broadcast through the air as radio waves from a transmitter to a radio antenna and, then, to a receiver. Stations can be linked in radio networks to broadcast common radio programs, either in broadcast syndication, simulcast or sub channels".

\subsubsection{Television}

Television is the product of the 1930s which unlike radio becomes more noticeable presence in 1948 and beyond because it combines the two powers of audio and sound (audio-visual) (Akinfeleye, 2011). He added that both the signals travel in a straight line in all directions and do not bounce up 
and down since the earth is not flat. Television broadcasting (telecast) is a television programming medium was long-awaited by the general public and rapidly rose to compete with its older radiobroadcasting sibling (Udomisor, 2013).

\subsection{Conventional Media Patronage in Nigeria}

Owuamalam (2007:46) defined an audience for the broadcast programme as group of individuals who converge at certain points where the television or radio sets are placed, in order to satisfy a purpose. The audience members tend to derive satisfaction from the programme they watch or listen to. Therefore, there must be some specific reactions for such audience to devout their time in respect of the programme. Not only radio and television, even newspaper has invariably the same pattern. Newspapers are obtained at newsstands where free readers gather to read headlines and other information thereby staging public discourse

Akpede (2010) argues that "members of the audience have various reasons for the consumption of specific programmes". For example, the US intervention in Middle East may appeal to different persons in various ways. It seems to some people as if US and its allies doing pursuing their interests. While others perhaps, would be interested in how those countries have reacted to the invasion of their country. Still others would want to know how world bodies like the United Nations have reacted. Yet some might want to know the reaction of the Arab League and other international organisations including humanitarian and even governmental organisations.

In Nigerian example, the Boko Haram crisis has been considered by many from different perspectives. Some still wage the blame on the government. To some, it is the mischief of the opposition party whilst many still believed that it is a religious crusade. It can now be seen that one news item satisfies segments of the audience in different ways. This brings us to how and why news is designed to meet the various aspirations of individual members of the audience through various ways. At times, programmes are produced mainly for local audience (Akpede, 2010). He added that in such circumstance, the programme may be conducted in the local language and the use of costumes and even make-up would be the ones prevalent in that area. A programme meant for a heterogeneous audience would be produced in the official or business language used by the audience, for example, English language would be used in the case of Nigeria. What brings the audience members together is the interest they have in the programme.

Akpede viewed the continuity to be "as soon as the programme expires the audience disperses". Such audience lacks leadership just like a crowd. Time for individual relationship and intimacy is limited by the duration of the programme. In one way or the other audience must be interested otherwise the members will not participate in the programme (Akpede, 2010).

The readership of newspaper, viewership of television and listenership of radio is still reigning in Nigeria. This is apparent considering the credibility they have maintained compared to the new media platforms (that were predicted to escort conventional media to extinction). Most homes in Nigeria have access to either of radio, television or newspaper. Sometimes one, duo or the trio are seen available in some homes especially in the urban areas. Udomisor (2013) stated that radio still maintain its dominance in the rural areas considering the expense involve in owning and operating television or the price of daily newspaper bulletin. In the urban areas, television is still waxing stronger as an instrument of luxury. This has helped in maintaining its significance as major source of information to the people. Even political authorities still used the television medium as the most reliable channels through which vital information can be communicated to the public, thus, increasing the level of patronage.

Among the young people nowadays, new media has taken over from the conventional media. Even though it was not fully but the rate is high. What kept some young people in the terrain of conventional media patronage is the inclusion of the conventional media channels in the smart phones. Mobile phones today have in-built radio and channels through which conventional media channels can be streamed. Newspapers are also on the internet and can be accessed all the time without constraints.

\subsection{Social Media: Component, Tools and Platforms}

The concept of social media through its history has been established to have technical complexity. From the foregoing social media can be said to have components, tools and platforms which were put 
together to yield the apparent results. According to Mayfield (2008) there are basically six kinds of social media even though he recognized the extensiveness of innovation. They include:

- Social networks: these sites allow people to build personal web pages and then connect with friends to share content and communication. The biggest social networks are MySpace, Facebook and Bebo.

- Blogs: it is possibly the best known form of social media; blogs are online journals, with entries appearing with the most recent first.

- Wikis: these websites allow people to add content to or edit the information on them, acting as a communal document or database. The best-known wiki is Wikipedia4, the online encyclopaedia which has over 2 million English language articles.

- Podcasts: audio and video files that are available by subscription, through services like Apple iTunes.

- Forums: areas for online discussion, often around specific topics and interests. Forums came about before the term "social media" and are a powerful and popular element of online communities.

- Content communities: communities which organise and share particular kinds of content. The most popular content communities tend to form around photos (Flickr), bookmarked links (del.icio.us) and videos (YouTube).

- Micro-blogging: social networking combined with bite-sized blogging, where small amounts of content ('updates') are distributed online and through the mobile phone network. Twitter is the clear leader in this field. (Mayfield 2008).

Almost similar to the above, Sajithra \& Rajindra (2013) outlined component of social media as:

1) Social Networking 2) Micro blogs 3) Blogs 4) RSS Feeds 5) Widgets 6) Linking and posting 7) Content Rating 8) Bookmarking sites 9) Audio podcasting 10) Video podcasting. Because this study has more focus on the social networking sites, two most popular examples were selected and reviewed.

\subsubsection{Twitter}

Originally intended for people to post answers to the question "What am I doing" in 140 characters or less, but has evolved into much more than that. It is useful for announcements, referrals and tag especially if you use hashtags (e.g \#SayYourMind, \#BBC, \#DailyTrust \#JoyPayne etc.). Hashtags begin with the \# symbol and are useful for returning targeted results from a search. Short URL services such as bit.ly help keep to the 140-character limit by shortening URLs to 20 characters or less (Mathews, n.d).

\subsubsection{Facebook}

Most people are familiar with Facebook, but in case you're not, it's the equivalent of a cocktail hour, where you may now \& then associate with people you've never met, but mostly you hang out with your friends. You can post "status updates" to let others know what you're doing, what you're thinking, where you're going, or just about anything else you want. You can post videos and photos, join groups, join fan pages, put things on the calendar, and on \& on. Privacy is a concern, but if you're careful, you don't really need to worry about it (Mathews, n.d).

\subsection{Impact of Social Media on Conventional Media}

Simply put, social media has vastly changed or influence the conventional media such as radio, television and newspaper. It has not stopped here because it also impacted the adjunct media such as Public relations and advertising as well as consumer behaviors towards these media.

The impact on conventional media has been opinionated by Agboola (2014) as "the days of loyalty to a particular news organization on a particular piece of technology in a particular form are gone". This means that the limitation of access and monopoly of the conventional media has been broken by the social media. Similarly, he added that the internet is at the center of the story of how people's 
relationship to news is changing. For instance Six in ten Americans (59\%) get news from a combination of online and offline sources on a typical day, and the internet is now the third most popular news platform, behind local television news and national television news. The local and national televisions news maintained their quo because of the issues of access and digital divide. Pew Research Centre (2012) cited in Agboola (2014) conducted a study and admits that most people say they use between two and five online news sources and others say they do not have a single favorite website for news. Some $21 \%$ say they routinely rely on just one site for their news and information (Pew Research Centre, 2012).

However, the internet has enormously changed people's experience of accessing news especially when internet is becoming a shared social experience as people swap links in emails, post news stories on their social networking site feeds, highlight news stories in their Tweets, and haggle over the meaning of events in discussion threads (Agboola, 2014). For instance, more than 8 in 10 online news consumers get or share links in emails (Pew Research Centre, 2012) cited in (Agboola, 2014). The rise of the internet as a news platform has been an integral part of these changes. The report of the Pew Research center discussed two significant technological trends that have influences news consumption behavior: First, the advent of social media like social networking sites and blogs has helped the news become a social experience in fresh ways for consumers. People use their social networks and social networking technology to filter, assess, and react to news. Second, the ascent of mobile connectivity via smart phones has turned news gathering and news awareness into an anytime, anywhere affair for a segment of avid news watchers (Pew Research Centre, 2012).

In Nigerian perspective Amaku (2012) expound that "the practice of journalism in the modern-day Nigeria is no longer an all-comers affair". Adding to this argument Agboola (2014) asserted that tertiary education combined with adequate professional training, as well as continuous skills acquisition is the hallmark of a modern-day journalist. Thus, to succeed in the practice of journalism, a 21 st century practitioner has no choice but to keep abreast of information technologies that have encroached and impacted on traditional journalism practice (Agboola, 2014).

He further commented that:

This is not only advisable, it is imperative for the journalist's continued
survival and relevance in an industry where the world no longer waits
for the news print or radio/TV to break the news. The world relies more,
these days, on the "new media" to provide on-the-go, real-time
information on the latest happenings around the world.

From the foregoing, Agboola (2014) contends that media houses from newspapers to TV stations are struggling to compete and stay relevant, as the reader can opt to be informed by Facebook status feeds or by following Tweets on Twitter or RSS feeds on whatever they fancy. Economically, newspapers and TV stations are being hit by declining ads revenues which is highly linked to the rise of the internet. Thus, other newspapers are viewing the move to internet-only publishing as their key to survival, as it cuts out overheads such as printing costs (Agboola, 2014).

\subsection{Theoretical Background}

The paper used Uses and Gratification Theory. The focus of this theory is on media use. Okunna (1999) observed that the functional use of mass communication is what the Uses and Gratification Theory explains. The Uses and Gratification Theory is also called Functional Theory. Katz, Blumler and Gurevitch (1974) summaries the main thrust of the theory as:

- "The audience is conceived as active."

- "In the mass communication process much initiative in linking gratification and media choice lies with the audience member."

- "The media compete with other sources of satisfaction."

- "Methodologically speaking, many of the goals of mass media use can be derived from data supplied by individual audience members themselves." 
- "Value judgments about the cultural significance of mass communication should be suspended while audience orientations are explored on their own terms."

The Uses of Gratification Theory is a media theory that was proposed to probe into why the media audience uses the media (What for?). It is an audience-based theory that proposes activeness of audience in relation to the media content. It proposition is based on what the audience use media for. This theory fits into this study to explain what the audiences patronize social media for and what do they patronize conventional media for. Another strong proposition of theory probes into the gratifications gained by the audience by virtue of using the media. This proposition came in consonance with the desire of this study to find out if there are incentives that instigate them to use either social or conventional media for their information need.

\section{Methodology}

According to Davies \&Modsell (2006), explanatory research is a systematic way of inquiry which is intended to explain why and how, rather than simply describing the phenomena under study. Survey has been selected as scientific methodology for the study. Survey is the most used methodology across professional, academic and other fields of study. Wilson, Esiri \& Onwubere (2008) defined survey as "a method for collecting and analyzing social data via highly structured and often very detailed interview or questionnaire in order to obtain information from large numbers of respondents presumed to be representative of a specific population". The population of this study is the total number of students of the University of Maiduguri, University of Maiduguri who have registered for 2017/2018 academic session. The total number of the registered is 33,666. In order to filter some elements of the population, the study covers all undergraduate students from level 100 to level 400 . To this end, all students who are not undergoing undergraduate programmes are unequivocally excluded.

This study adopted the use of Purposive Sampling. Purposive sampling is a non-probabilistic sampling technique where the researcher intentionally selects certain groups or individuals as samples mainly because of their relevance to the investigation being carried out (Adefila, 2008; Fajonyomi \& Fajonyomi, 2003). The reason for selection of this technique is that, the data required by the study is peculiar to individuals who know about it (the data is about the media audience patronage of either conventional media or social media). From the 33,666 the study purposively selected 200 sample from four faculties which are; Faculty of Social Sciences 50, Faculty of Arts 50, Faculty of Management Sciences 50, and Faculty of Education 50 to conduct the study. The yardsticks used for the selection of the respondents include noticeable familiarities with media consumption and ability to distinguish between conventional media and social media. The selected this sample to simplify the conduct of the study and acquire data from well informed respondents.

The Questionnaire has been adopted as a tool for data collection. Questionnaire is a survey instrument, the questionnaire is an instrument used for obtaining information from respondents in a systematic way. According to Adefila (2008) it is a special form of correspondence developed to procure authoritative information from a number of persons through the medium of well-directed questions. Fajonyomi and Fajonyomi (2003) outlined two types of questionnaire; the open-ended and close-ended questionnaire. To control the conduct of the study within the time range and resources available, the study used the close-ended questionnaire. The questionnaires were designed in simple language with utmost precision. It was self-administered through direct (hand delivery) method. The data collected would be presented in quantitative form after which meaning would be titrated from the raw data. The study used questionnaire to collect quantitative data. Mixture of tables, percentages, and numerical were employed to facilitate the data presentation and analysis. Finally, step-by-step answering research questions and discussion of findings will follow.

\section{Presentation of Data}

The study administered 200 questionnaires to students of the University of Maiduguri. The questionnaire was divided into two major categories. The first category collected demographic information of the respondents while the second part asked questions that best serve the objectives of the study. The data below present the response of the students regarding the topic under study. 
Comparative Analysis of Social and Conventional Media Patronage among University Students: A Case Study of University of Maiduguri

\subsection{Demography of the Students}

Table1: Gender Distribution of the Respondents

\begin{tabular}{|l|l|l|l|}
\hline $\mathbf{S} / \mathbf{N}$ & \multicolumn{1}{|c|}{ Response } & \multicolumn{1}{c|}{ Frequency } & \multicolumn{1}{c|}{ Percentage } \\
\hline 1 & Male & 117 & $58.5 \%$ \\
\hline 2 & Female & 79 & $39.5 \%$ \\
\hline 3 & Others & 4 & $2 \%$ \\
\hline
\end{tabular}

Source: Survey, 2019.

In the table above, the study sampled was constituted by 117 respondent representing $58.5 \%$ male students, 79 respondents representing 39.5\% female students and 4 others who are neither male nor female. This means that majority of the respondents that were sampled are male students. This is because most of the male students exhibit high responsiveness to purposive selection than female students.

Table2: Age Categorization of the Respondents

\begin{tabular}{|l|l|l|l|}
\hline S/N & \multicolumn{1}{|c|}{ Response } & \multicolumn{1}{|c|}{ Frequency } & \multicolumn{1}{|c|}{ Percentage } \\
\hline 1 & $18-21$ years & 10 & $5 \%$ \\
\hline 2 & $22-25$ years & 97 & $48.5 \%$ \\
\hline 3 & $26-29$ years & 60 & $30 \%$ \\
\hline 4 & 30 and above & 33 & $16.5 \%$ \\
\hline \multicolumn{2}{|c|}{ Total } & 200 & $100 \%$ \\
\hline
\end{tabular}

Source: Survey, 2019.

In the table above, age variation indicated that 10 respondents representing 5\% belong to $18-21$ years age category, 97 respondent equivalent to $48.5 \%$ belong to 22.25 age category, 60 respondents representing $30 \%$ were aged between 26 to 29 while 33 representing $16.5 \%$ were aged 30 and above. This means that majority of the respondents are youths presenting high level of exposure to social media. However, the last category of 30 and above presents a representation of older people who are presumed to have more passion for conventional media. this indicate adequate representation in the sample.

Table3: Academic Level of the Students

\begin{tabular}{|l|l|l|l|}
\hline S/N & \multicolumn{1}{|c|}{ Response } & \multicolumn{1}{c|}{ Frequency } & \multicolumn{1}{c|}{ Percentage } \\
\hline 1 & 100 Level & 8 & $3.5 \%$ \\
\hline 2 & 200 Level & 33 & $16.5 \%$ \\
\hline 3 & 300 Level & 62 & $31.5 \%$ \\
\hline 4 & 400 Level & 97 & $48.5 \%$ \\
\hline \multicolumn{2}{|c|}{ Total } & 200 & $100 \%$ \\
\hline
\end{tabular}

Source: Survey, 2019.

The above table shows that more students were selected from the higher class than the lower class. It shows that only 8 respondents representing 3.5\% were selected from first year class, 33 respondents representing $16.5 \%$ were selected from second year class, 62 respondent representing $31.5 \%$ were selected from third year class and highest number 97 respondents representing $48.5 \%$ were selected from final class. The parameter set for the purposive sampling is the major determinant of the above figures.

Table5: Do you patronize media?

\begin{tabular}{|l|l|l|l|}
\hline \multicolumn{1}{|c|}{ S/N } & \multicolumn{1}{|c|}{ Response } & \multicolumn{1}{c|}{ Frequency } & \multicolumn{1}{c|}{ Percentage } \\
\hline 1 & Yes & 200 & $100 \%$ \\
\hline 2 & No & 0 & $0 \%$ \\
\hline Total & 200 & $100 \%$ \\
\hline
\end{tabular}

Source: Survey, 2019.

The result presented in the above table indicated complete agreement of the respondents that they patronize media (either social or conventional as contextualized by this research). This justify the purposive selection made by the study which target respondents who patronize media either 
conventional media or social media. In this regard, adequate responses are obtained from well informed respondents and possibilities of errors are highly eliminated by the purposive sample.

Table6: Which type of media do you patronize?

\begin{tabular}{|l|l|l|l|}
\hline S/N & \multicolumn{1}{|c|}{ Response } & \multicolumn{1}{c|}{ Frequency } & \multicolumn{1}{c|}{ Percentage } \\
\hline 1 & Conventional Media & 79 & $39.5 \%$ \\
\hline 2 & Social Media & 100 & $50 \%$ \\
\hline 3 & Both (Social and Conventional) & 21 & $10.5 \%$ \\
\hline Total & 200 & $100 \%$ \\
\hline
\end{tabular}

Source: Survey, 2019.

The table above contained data collected from the respondents with regard to the type of media they patronize. It shows that 79 respondents which is equivalent to $39.5 \%$ patronize conventional media, 100 respondents which constituted 50\% patronize social media while 21 respondents which constituted $10.5 \%$ patronize both social and conventional media. This reveals that there is high patronize of social media compared to conventional media. However, there is little number of the respondents who patronize both social and conventional media. This can be related the fact that so many people have accepted the social media and abandoned the conventional media even though there are still some people who believe in conventional media because they perceive social media as unserious media that contain non-credible and unreliable information. It is also related to the fact that social media allow every user to post a story without proper verification or vetting.

Table7: How often do you patronize the type of media you choose in previous questions?

\begin{tabular}{|l|l|l|l|}
\hline S/N & \multicolumn{1}{|c|}{ Response } & \multicolumn{1}{c|}{ Frequency } & \multicolumn{1}{c|}{ Percentage } \\
\hline 1 & Most Often & 71 & $35.5 \%$ \\
\hline 2 & Often & 80 & $40 \%$ \\
\hline 3 & Rarely & 49 & $24.5 \%$ \\
\hline 4 & Very Rare & 0 & $0 \%$ \\
\hline Total & 200 & $100 \%$ \\
\hline
\end{tabular}

Source: Survey, 2019.

The above table contains data on the frequency of patronage of either social media or conventional media. The data contain herein can be analyzed from two directions; the direction of the social media and direction of the conventional media. According to the table, 71 respondents which is equivalent to $35.5 \%$ patronize the media they choose with utmost frequency, 80 respondents which equates $40 \%$ often patronize the media they choose while 49 respondents which represent $24.5 \%$ rarely patronize the media they choose. In this sense, the result shows that social media still maintain high patronize from it 50\% respondent while the conventional continue to lag behind with fewer respondents. However, for the category that suggested the patronage of both social and conventional media, it entails their huge commitment to media patronage. Such respondents are presumed to be more versatile.

Table8: How much time do you spend patronizing the media you choose in question?

\begin{tabular}{|l|l|l|l|}
\hline S/N & \multicolumn{1}{|c|}{ Response } & \multicolumn{1}{|c|}{ Frequency } & \multicolumn{1}{|c|}{ Percentage } \\
\hline 1 & 30Minutes-1Hour a day & 45 & $22.5 \%$ \\
\hline 2 & 2Hours-4Hours a day & 102 & $51 \%$ \\
\hline 3 & 5Hours-8Hours a day & 20 & $10 \%$ \\
\hline 4 & 9Hours-12Hours a day & 25 & $12.5 \%$ \\
\hline 5 & 13Hours and above a day & 8 & $4 \%$ \\
\hline Total & 200 & $100 \%$ \\
\hline
\end{tabular}

Source: Survey, 2019.

To determine the specific level of the patronage, the study sought to know the amount of time the respondents dedicate to patronage of the type of media they choose. The table above presents their response. The result shows that 45 respondents representing $22.5 \%$ patronize the media between 30 minutes to 1 hour a day, 102 respondents representing 51\% patronize the media between 2 hours to 4 hours a day, 20 respondents representing $10 \%$ patronize the media between 5 hours to 8 hours a day while there are 25 respondents representing $12.5 \%$ who patronize the media between 9 hours to 12 
hours a day. This category can be referred to as media addicts. Such are often found with the usage of social media. Finally, 8 respondents representing $4 \%$ use the media for 13 hours and above a day. This category can be termed as media-glued. This is for the fact from the 24 hours of a day, they spend more than half with media. This is reflective of some people who patronize both social media and conventional media. In this regard, the former media complement the latter.

When asked if they have preference between the conventional media and social media, most of the respondents indicated that they have preference of one media over the other. 182 respondents representing $91 \%$ agreed that they have preference while 18 respondents representing $9 \%$ do not have preference. For those that have preference reason would be sought for while the latter category tells about some media audience who patronize media based on its availability. To this end, they patronize the media available at a time which could be social media or conventional. Put simple, patronage of conventional media requires power for radio and television and money for newspaper purchase. In the absence of light or money to buy newspaper, the audience has no option of access. On the other hand, the access to social media requires data connection which in its absence access cannot be guaranteed. This explains why some audience uses both social and conventional media to access information so that each will complement the other.

Table10: Which media do you prefer?

\begin{tabular}{|l|l|l|l|}
\hline \multicolumn{1}{|c|}{ S/N } & \multicolumn{1}{|c|}{ Response } & \multicolumn{1}{c|}{ Frequency } & \multicolumn{1}{c|}{ Percentage } \\
\hline 1 & Conventional Media & 71 & $39.02 \%$ \\
\hline 2 & Social Media & 111 & $60.98 \%$ \\
\hline Total & 182 & $100 \%$ \\
\hline
\end{tabular}

Source: Survey, 2019.

In this table, the 182 respondents representing $91 \%$ of the total sampled respondents who asserted to have preference of media were asked the type of media they prefer. The table shows that 71 respondents representing $39.02 \%$ prefer to patronize the conventional media while 111 respondents representing $60.98 \%$ prefer the social media to conventional media. This indicates the dominance of social media preference among the respondents. Social media appeared to be the preferred media to most of the respondents even though significant number of the respondents maintained preference to the conventional.

Table11: What are the reasons for your preference?

\begin{tabular}{|l|l|l|l|}
\hline \multicolumn{1}{|c|}{ S/N } & \multicolumn{1}{|c|}{ Response } & \multicolumn{1}{c|}{ Frequency } & \multicolumn{1}{c|}{ Percentage } \\
\hline 1 & Accuracy and reliability of Information & 53 & $26.5 \%$ \\
\hline 2 & Instant messages and update & 79 & $39.5 \%$ \\
\hline 3 & Interactivity and participatory nature of media & 30 & $15 \%$ \\
\hline 4 & $\begin{array}{l}\text { Quality of Content in terms of Spelling, } \\
\text { Grammar etc }\end{array}$ & 18 & $9 \%$ \\
\hline 5 & All of the above & 20 & $10 \%$ \\
\hline Total & 200 & $100 \%$ \\
\hline
\end{tabular}

Source: Survey, 2019.

The above table presents the reasons for the preferences of the respondents. The table shows that 53 respondents representing $26.5 \%$ prefer conventional media over social media because of accuracy of information, 79 respondents representing $39.5 \%$ depend on the reliability of the information carried by the media for preference. This means that they depend on a particular media because of its reliability. This can be applied to both conventional and social media. Because, it is now a trend that conventional media have social media accounts where information is shared. There are 30 respondents representing $15 \%$ who depend on source of information to make preference according to this category, lack of reliable source to information affect their preference of media either social or conventional. In another divergent idea, 18 respondents representing 9\% consider the elements of writing to judge their preference. This category considers grammar, spelling etc as parameter for judging media they patronize. It can be argued it here that the elements of writing have enormous influence on how audience perceives the credibility of particular information at a time. Significantly, 20 respondents representing $10 \%$ use all the above stated reason for selection of the media they use. 
By implication, accuracy, reliability, good standard writing and professional structured content is the reason for their preference. To this end, it can be argued that such reasons for more skewed to the conventional media than the social media.

The respondents were asked to provide the degree to which these reasons influence their patronage of the type of media they prefer. The question here sought for qualitative response. Majority of the respondents suggested that the participatory nature of social media makes it speedy. This feature is the main reason for their high patronage of the type of media they patronize. There are respondents who prefer social media instantaneous update and such has lead to often refreshing of their pages. The reliability of conventional media is what pilot more patronage of their content among some of the respondents. Conventional media influences the audience more than the social media because of its reliable content while social media retain high patronage for its speed and versatility of content. This finally entails that the reason for the preference of a particular media play significant role on the degree to which the respondents patronize the media.

Table12: Do you rely on information you get from social media?

\begin{tabular}{|l|l|l|l|}
\hline S/N & \multicolumn{1}{|c|}{ Response } & \multicolumn{1}{c|}{ Frequency } & \multicolumn{1}{c|}{ Percentage } \\
\hline 1 & Yes & 121 & $60.5 \%$ \\
\hline 2 & No & 79 & $39.5 \%$ \\
\hline Total & 200 & $100 \%$ \\
\hline
\end{tabular}

Source: Survey, 2019.

The above table shows the response measuring the reliability of the respondents on social media. It shows that 121 respondents representing $60.5 \%$ who rely on information they see on social media while 79 respondents representing $39.5 \%$ who do not rely on information they see on social media. This means that despite having high number of people who believe in social media there is still significant number who do not rely on such information as reliable. This also exhibits the doubt on credibility of information on social media. However, the high number realized on category that relies on social media can be attached to the fact that reliable conventional media share information on social media. This is added to the new way of verifying accounts made by Twitter, Facebook etc to facilitate the credibility of information being posted.

Table13: Do you rely on information you get from conventional media?

\begin{tabular}{|l|l|l|l|}
\hline S/N & \multicolumn{1}{|c|}{ Response } & \multicolumn{1}{c|}{ Frequency } & \multicolumn{1}{c|}{ Percentage } \\
\hline 1 & Yes & 188 & $94 \%$ \\
\hline 2 & No & 12 & $6 \%$ \\
\hline Total & 200 & $100 \%$ \\
\hline
\end{tabular}

Source: Survey, 2019.

In the above, the study sought to know if the respondents rely on information they get from conventional media. The data shows that 188 respondents representing $94 \%$ rely on information they get from conventional media while 12 respondents representing $6 \%$ do not rely on information they get from conventional. To this end, the conventional media has continued to retain its position as the most reliable information source despite conquer from the social media. This is supported by the fact that only $6 \%$ of the respondents do not rely on information from conventional media which has less or no significance. The high reliability was realized because of professional creed and censorship that has to be done before releasing information on conventional media.

Table14: What is your degree of reliance on the type of media you patronize?

\begin{tabular}{|l|l|l|l|}
\hline $\mathbf{S} / \mathbf{N}$ & \multicolumn{1}{|c|}{ Response } & \multicolumn{1}{c|}{ Frequency } & Percentage \\
\hline 1 & Perfect Reliance & 72 & $36 \%$ \\
\hline 2 & More Reliance & 60 & $30 \%$ \\
\hline 3 & Less Reliance & 30 & $15 \%$ \\
\hline 4 & Doubtful Reliance & 30 & $15 \%$ \\
\hline 5 & No Reliance & 8 & $4 \%$ \\
\hline Total & 200 & $100 \%$ \\
\hline
\end{tabular}

Source: Survey, 2019. 
The last table presents information on the degree of respondents' reliance on the media they prefer to patronize. It indicates that 72 respondents representing $36 \%$ perfectly rely on such media without a single element of doubt at all times. There are 60 respondents representing 30\% who rely on such media more than otherwise. To this end, absence of doubt is not total. There are 30 respondents representing $15 \%$ who have less reliance on the information they get from the media they prefer to patronize. The doubt in this category is higher than previous. Similarly, there are 30 respondents representing $15 \%$ who rely on the information but with much element of doubt. Lastly, fewest categories of the respondents 8 which represent $4 \%$ do not rely on information they received whatsoever. This category expressed highest degree of doubt on content of the media they patronize.

The study also sought to know the reasons behind the reliance of the respondents and found that;

- Rumors carried on social media contain facts that are true sometimes.

- Because of the facts, information and educative content.

- The information is genuine.

- They research for the facts before spreading to the world.

- They are professionally trained and follow rules as guide in the dissemination of information.

- They are accurate fast and reliable.

- Because they provide past information

\section{KEY FINDINGS OF THE STUDY}

The study found that:

- The patronage of media (either social or conventional) among students is absolutely positive. Simply put, every student patronizes either social or conventional media.

- Social media has higher level of patronage compared to the conventional media among the students and their patronage.

- There is high commitment of the students to the type of media they patronize. According to this finding, the higher number obtained from patronage of social media influence level of commitment in this finding. This further means that degree of patronage of social media is higher than conventional media.

- The amount of time audience allocates to the patronage of media either social or conventional is huge. This finding is also influenced by the first finding regarding the number of those that patronize conventional and social media. This means the amount of time spent on social media is higher than the conventional media by the students.

- There is exorbitant preference to the social media than conventional media.

- There is still significant number of audience who prefer the conventional media to social media.

- Audiences prefer conventional media because of accuracy and reliability of information. Professionalism and standard in ethics, spelling and grammar are also influential reason on their preference of conventional media.

- Audiences prefer social media for instant messages and updates found on the platforms. However, interactivity and participatory nature play significant role on their preference of social media.

- Each of the media influence its audience based peculiar characteristic and features which pilot the level of patronage. Because some like more interactivity and participation, the social media is waxing strong in this respect while the conventional media keep soaring higher among those who prefer reliable and accurate information that been professionally verified.

- Most of the audiences rely on information they receive from the social media even though significant number $(39.5 \%)$ still doubt the reliability of such information.

- Almost all audiences rely on conventional media. The number $(6 \%)$ of those who do not rely on such information is less or no significance. 
- The degrees of reliance vary across the audience.

\section{DISCUSSION OF FINDINGS}

\subsection{Objective1: To Examine the Level of Patronage of Conventional and Social Media by Students of University of Maiduguri}

The emergence of social media has posed a big threat to the existing conventional that had served the information need of the public for a long period time. It is a media that has arrives with peculiar feature to lure the attention of audience especially the youth. Interactivity and participatory natures are significant in this respect. As a result, various pessimisms were expressed by various scholars and media practitioners that social media could take over the position of the conventional media. This study found that part of this pessimism is now realistic. Social media has higher level of patronage compared to the conventional media among the students and their patronage as found by this study is a good justification that the social media is now a threat to conventional media.

Put simple, the social media is engulfed with other features that enable the audience to commit themselves to it than the conventional media. The study found that there is high commitment of the students to the type of media they patronize. According to this finding, the higher number obtained from patronage of social media influence level of commitment in this finding. This further means that degree of patronage of social media is higher than conventional media. The social media are friendly in terms of use and responsive to the inquiry of the audience. This enables longer stay of the audience in its patronage. However, the social media is a portable media unlike television and more than more portable than radio and newspaper. Social media can be accessed through mobile phones which can be pocketed easier than radio and newspaper. This has enables more user to carry phone along and access their social media pages everywhere at leisure time. As such, audience can use social media at work, public places, home etc. Against this background, the study found that the amount of time audience allocates to the patronage of social media is huge. This finding is also influenced by the first finding regarding the number of those that patronize social media. This means the amount of time spent on social media is higher than the conventional media by the students.

\subsection{Objective2: To Find Out the Reasons for the Preference of Either Social or Conventional Media by Unimaid Students}

As thrust before, the social media is spicy and friendly than conventional media while the conventional media is feasibly more standard. This entails that each of the social and conventional media has exclusive features that can generate audience. To this end, the study tested the comparative capacities of the two and found that there is exorbitant preference to the social media than conventional media. Because the students sampled are youths, this finding is not a big surprise. This is because the social media is design with spicy features to generate the attention of youth who glorify fashionable things. To this end, the students vehemently preferred the social media to conventional media.

However, the conventional media is a bit lagging behind in terms of preference. The study found that there is still significant number of audience who prefer the conventional media to social media. The tone of the finding indicates that the level of preference of conventional media is not up to the level of social media. Understandably, preferences are driven by certain reasons. In this regard, the study sought to know if there reason behind the preferences of social and conventional media among the students. It was found that audiences prefer conventional media because of accuracy and reliability of information. Professionalism and standard in ethics, spelling and grammar are also influential reason on their preference of conventional media. This study contest the pessimism expressed by scholars that social media might wipe away conventional media. This is because conventional is and always will be more reliable than social media because content of conventional media are professionally crafted and verified. By extension, it means every story seen on the conventional media must have undergone serious vetting and gate-keeping will likely to be accurate than stories found on conventional media that are merely posted by users who think not about accuracy or reliability.

On the other hand, the study found that audiences prefer social media for instant messages and updates found on the platforms. However, interactivity and participatory nature play significant role on their preference of social media. In this respect, the study argues that even though conventional 
media could retain certain percentage of audience preference, the friendliness of social media is a threat to shrinking the space it occupies in the framework of information dissemination. On the level of influence, the study measured how these reasons of preference influence the mode of patronage and found that each of the media influence its audience based on peculiar characteristic and features which pilot the level of patronage. Because some like more interactivity and participation, the social media is waxing strong in this respect while the conventional media keep soaring higher among those who prefer reliable and accurate information that been professionally verified.

\subsection{Objective3: To Determine the Reliance of the Students on Either Social Media or Conventional Media}

Patronage and level of reliance are different variable in this context. The study presumed that there could be audience who patronize certain media but do not always rely on information they obtain from such media. On this basis, the study measured the level of reliability on conventional media and level of reliability on the social media and found that most of the audiences rely on information they receive from the social media even though significant number $(39.5 \%)$ still doubt the reliability of such information. This entails that even with high patronage it secure, the social media is yet to win the confidence of some audience who still indicate doubt on the information the social media carries. This can be attributed to the no-vetting policy used by social media pages. However, even if the social media intends to initiate vetting system it will end up restricting the freedom of information and expression it has been praised for its guarantee to the audience.

The study found that almost all audiences rely on conventional media. The number $(6 \%)$ of those who do not rely on such information is less or no significance. In this sense, despite the conquest of the social media, the conventional media has retained its credibility having steep number of its audience who rely on its information dissemination system. The study also found the degree reliance varies across the audience.

\section{CONCLUSion}

The social media emergence has spurred so many arguments and raised eye-lids where experts predict its dominance over conventional media. Their pessimisms have since been established to have elements of truth and realistic. Nonetheless, there are still features that help conventional media endure the conquest of the social media. Despite the fact that social media have assumed high patronage it has failed to secure credibility and reliability to win the confidence of the audience. To these various end, the study concludes that nature, values, features and principles of conventional media will help it to never vanish in the information dissemination system. This is because the social media does not have capacity needed to replace the conventional media. The study however argues that even though audience need friendly and participatory media the credibility, reliability cannot be undermined.

\section{REFERENCES}

[1] Acheaw, O. \& Larson, A. (2015). Use of social media and its impact on academic performance of tertiary institution students: A study of students of Koforidua Polytechnic, Ghana. Journal of education and practice, 6(6).

[2] Adefila, J. J. (2008). Research methodology in behavioural science. Kaduna; Apani Publications. Pp.9-11.

[3] Agboola, A. K. (2014). The influence of new media on conventional media in Nigeria. Academic research international, 5(4), pp. 1-9.

[4] Ahmad, M. A. (2016). The complexities of new media: can the 'web media' completely erase traditional media from the communication industry? International journal of network and communication research vol.3, no.2, pp.31-46,

[5] Akinfeleye, R. A. (2011). Essentials of journalism: An introductory text. Lagos; Malthouse Press Limited. Pp. 55-59

[6] Akpede, K. S. (2010). Introduction to radio and television. Lagos; National Open University of Nigeria. ISBN: 978-058-116-2.

[7] Anderson, C. W. (2011). Deliberative, agonistic and algorithmic audience: Journalism's vision of its public in an age of audience transparency. International journal of communication, 5, pp.529-547. 
[8] Balarabe, S. (2013). Digitization of television broadcasting in Nigeria: Review. International journal of social sciences, Human science and engineering, 7(10), pp.129.

[9] Baran, S. J. \& Davis, D. K. (2012). Mass communication theory: Foundation, ferment and future. Boston; Wadsworth Cengage Learning.

[10] Blumler, J. G. \& Katz, E. (1974). The uses of mass communications: Current perspectives on gratifications research. Beverly Hills, CA: Sage.

[11] Davies, M. \&Mosdell, N. (2006). Practical research methods for media and cultural studies: Making people Count. Edinburg: Edinburgh University Press.

[12] Dewing, M. (2010). Social media: An introduction. Ottawa: Library of Parliament. Publication No. 201003-E pp. 1-8.

[13] Eke, H. N., Omekwu, C. O. \&Odoh, J. N. (2014). The Use of Social Networking Sites among the Undergraduate Students of University Of Nigeria, Nsukka. Library philosophy and practice (e-journal), 1195.

[14] Evborokhai, J. (20003). A Practical Guide to Research Writing: for Polytechnic and Universities. Bida: Jube-Evans Books and Publications.

[15] Fajonyomi, A. A. \&Fanjonyomi, M. G. (2003). Research process in education and social sciences. Lagos; Goldy O Publishing Company. Pp. 48-61.

[16] Gaudeul, A. \& Peroni, C. (2010). "Reciprocal attention and norm of reciprocity in blogging networks". Economics Bulletin, 30(3), pp. 2230-2248

[17] Harmanci, R. (2005). "Time to get a life - pioneer blogger Justin Hall bows out at 31". San Francisco Chronicle. Retrieved 2018-02-01.

[18] Idebi, S. K. (2008). Fundamentals of Radio Production. Ibadan: Impact Motion Pictures and Media Koncept Nig.

[19] Ikime, O. (1979). “20th Anniversary History of NTV.” Ibadan: 1st Photo RAMA: Ibadan, NTV.

[20] Jones, S. (2002). "Internet Relay Chat". Encyclopedia of New Media: An Essential Reference to Communication and Technology (1st ed.)

[21] Kumar, R. (1996) Research Methodology: step by step guide for Beginners. London: Sage Publications.

[22] Kuyucu, M. (2014). New communication technologies and journalism. The creation of New multimedia newspaper with Miliyet Newspaper and Blippar. International conference on communication, media, technology and design. Istanbul; Istanbul Aydin University.

[23] Mayfield, A. (2008). What is social media? An e-book by Anthony Mayfield from i-crossing. San Francisco, California, USA.

[24] Mcnamara, J. (2014). Which media set the news agenda: mass media or/and social media? An independent research report sponsored by iSentia.

[25] Odun, O. \&Utulu, A. U. (2016). Is the new media superior to the traditional media for advertising? Asian journal of economic modeling, 4(1), pp. 57-69

[26] Okoro, N., Diri, C. T. \&Odii, C. (2013). Citizen journalism in Nigeria: Possibilities and challenges. New media and Mass communication, Vol.11, pp. 1-7.

[27] Okunna, S. C. (1999). Introduction to Mass Communication. Enugu; New Generation Book.

[28] Onuoha, P. (2012). History of Nigerian mass media. A study material published by National Open University of Nigeria. Pp.13 ISBN: 978-058-779-9

[29] Osborn, B. (2001). Ethics and credibility in online journalism. JOUR 6702: Current issues in journalism. Memphis; University of Memphis.

[30] O’Reilly, T. (2005). What Is Web 2.0? sourced on 28/03/2018 from http://www.oreilly.de/artikel/web20. html.

[31] O’Reilly, T. \& John, B. (2009). Web Squared: Web 2.0 Five Years On. Special report. Sourced on 28/03/2018 from http://assets.en.oreilly.com/1/event/28/web2009_websquared-whitepaper.pdf.

[32] Sajithra, K. \&Rajindra, P. (2013). Social media- history and components. IOSR journal of business and management, 7(1), pp. 69-74.

[33] Stern, G. (1999). This web-based services critiques online media. Link-Up, 16(1), pp.21.

[34] Trottier, D. \& Fuchs, C. C. (n.d). Theorizing social media, politics and the state.

[35] Udomsior, I. W. (2013). Management of radio and television in Nigeria. New media and communication, 10, pp. 1-13. 
[36] Veil, S. R., Buehner, T. \&Palenchar, M. J. (2011). “A Work-In-Process Literature Review: Incorporating Social Media in Risk and Crisis Communication." Journal of Contingencies and Crisis Management, 19(2), pp. 111-122.

[37] Wimmer, R. \& Dominick, J. (2006). Mass Media Research: An Introduction. Belmont, CA: Walworth.

[38] Wilson, D., Esiri, M. \&Onwubere, C. H. (2008). Communication research. Published by National Open University of Nigeria. ISBN 978-058-533-8.

[39] Yeshua, D. \&Deuze, M. (2000). Online journalist face new ethical dilemmas: Report from the Netherlands. Amsterdam; ASCor

Citation: Mohammed Auwal Umar, Fredrick Wilson. "Comparative Analysis of Social and Conventional Media Patronage among University Students: A Case Study of University of Maiduguri". International Journal of Media, Journalism and Mass Communications (IJMJMC), vol 5, no. 4, 2019, pp. 32-48 doi: http:// dx.doi.org/10.20431/2455-0043.0504004

Copyright: (C) 2019 Authors. This is an open-access article distributed under the terms of the Creative Commons Attribution License, which permits unrestricted use, distribution, and reproduction in any medium, provided the original author and source are credited. 